\title{
pro.posições
}

$e$-ISSN 1980-6248

http://dx.doi.org/10.1590/1980-6248-2016-0011

ARTIGOS

\section{Avaliação externa nas classes de alfabetização no Espírito Santo}

\section{External assessment in literacy classes in the state of Espírito Santo}

Dilza Côco (i)

Cláudia Maria Mendes Gontijo (ii)

\begin{abstract}
(i) Instituto Federal de Educação, Ciência e Tecnologia do Espírito Santo - IFES, Vitória, ES, Brasil, dilzacoco@gmail.com

(ii) Universidade Federal do Espírito Santo - UFES, Vitória, ES, Brasil, clammgont@gmail.com.br
\end{abstract}

Resumo: O artigo objetiva compreender os sentidos produzidos para o Programa de Avaliação da Educação Básica do Espírito Santo - Alfabetização (Paebes-Alfa). Utiliza como referencial teórico contribuições do círculo de Mikhail Bakhtin e adota o estudo de caso como metodologia de pesquisa. Privilegia a análise dos diálogos com e dos sujeitos participantes do programa. Integram o corpus da pesquisa fontes documentais e registros dos diálogos durante a aplicação dos testes de avaliação de Língua Portuguesa realizada em salas de $1 .^{\circ}$ e $2 .^{\circ}$ anos do Ensino Fundamental. Conclui, apesar do caráter impositivo e prescritivo do Paebes-Alfa, que os sujeitos produzem posicionamentos críticos sobre o programa, subvertendo a ordem imposta.

Palavras-chave: avaliação externa, alfabetização, leitura, escrita

Abstract: The article aims at understanding the meanings produced for the Assessment of Elementary Education Programme of Espirito Santo - Literacy (Paebes-Alfa, from the Portuguese Programa de Avaliação da Educação Básica do Espírito Santo - Alfabetização). It uses the contributions from the Bakbtin Circle as its theoretical framework and it adopts case study as a research methodology, emphasizing the analysis of dialogues with and of the Programme's participating subjects from one of the municipalities of Espirito Santo. The research corpus is constituted by documentary sources and records of dialogues during the application of Portuguese Language assessment tests carried out in first and second grade Elementary School classrooms. Despite the authoritative and prescriptive character of the Paebes-Alfa, the research concludes that the subjects produce critical perspectives toward the Programme, subverting the imposed order.

Keywords: external evaluation, literacy, reading, writing 


\section{pro.posıções}

http://dx.doi.org/10.1590/1980-6248-2016-0011

\section{$e$-ISSN 1980-6248}

\section{Introdução}

A criação e a implantação de sistemas de avaliação externa, em larga escala, no contexto educacional brasileiro, assim como em outros países (Bauer, 2010; Ravitch, 2011), têm se consolidado como política pública estatal dirigida a vários níveis de ensino. Na educação básica, avaliações dessa natureza têm ganhado força e ampliado o público-alvo envolvido. Desde os anos 1990, identificamos iniciativas do governo brasileiro na condução e na implantação desse tipo de avaliação (Freitas, 2007), como as que integram o Sistema de Avaliação da Educação Básica (Saeb), regulamentado em 1992. Notamos, desde então, uma trajetória de investimentos, aprimoramentos e ampliação do Saeb, o que indica a centralidade que esse tipo de avaliação ocupa no cenário das políticas públicas educacionais a partir dos anos de 1990.

No que diz respeito à ampliação dos sistemas de avaliação, podemos indicar a inclusão da fase inicial de alfabetização como foco de levantamento de dados do Saeb. Em 2013, por meio da Portaria de n. 482, do Ministério da Educação (MEC), foi criada a Avaliação Nacional da Alfabetização (ANA) como integrante do Saeb. Essa avaliação, direcionada às crianças matriculadas em turmas de $3 .^{\circ}$ ano do Ensino Fundamental, anuncia como um de seus objetivos produzir informações sobre conhecimentos dos alunos relacionados à Língua Portuguesa e Matemática, visando a uma melhoria da qualidade da educação. No entanto, a ideia de uma avaliação externa educacional como necessária ao alcance de uma pretensa melhoria da qualidade tem gerado debates e problematizações, pois vincula a noção de qualidade aos resultados obtidos apenas em provas.

Autores - como Azevedo (2011), Cabrito (2009), Casassus (2009), Silva (2008) e muitos outros -, que dedicam atenção ao tema mostram a complexidade do termo "qualidade" na área educacional. Cabrito (2009) afirma que a noção de qualidade migrou da esfera econômica e financeira para a educativa e destaca que a transposição de conceitos de um setor para outro distinto exige cautela e ponderações para não correr riscos de simplificações.

No campo da alfabetização, as políticas de avaliação, desenvolvidas pelo MEC, em parceria com o Instituto Nacional de Estudos e Pesquisas Educacionais Anísio Teixeira (Inep), podem ser consideradas recentes, pois tiveram início com a institucionalização da Provinha Brasil em 2007, seguida da ANA, conforme já mencionado. Concomitantemente a essas 


\section{pro.posıções}

http://dx.doi.org/10.1590/1980-6248-2016-0011

$e$-ISSN 1980-6248

iniciativas patrocinadas pela instância federal, muitos estados e municípios acompanham essa tendência, criando sistemas próprios de avaliação.

Brooke, Cunha e Faleiros (2011), em levantamento realizado até o ano de 2011, mostraram que 19 estados da federação brasileira possuíam sistemas próprios de avaliação. Sobre essa disseminação, Freitas (2007) indica que as várias iniciativas estaduais e até mesmo no âmbito de municípios constituem campo fértil de investigação, pois o conhecimento sobre as apropriações e as repercussões dessas avaliações ainda é muito restrito.

É desse cenário de possibilidades para novos estudos que se origina este artigo. Ele tem por objetivo problematizar a avaliação externa na educação do Espírito Santo a partir de resultados de uma pesquisa mais ampla. Especificamente, buscamos analisar ações vinculadas ao Programa de Avaliação da Educação Básica do Espírito Santo (Paebes) no contexto do ciclo de alfabetização, denominado de Paebes-Alfa, com a intenção de compreender sentidos produzidos para essa avaliação, especialmente pelos sujeitos que habitam o espaço-tempo da sala de aula. Para isso, organizamos as discussões deste texto em cinco partes, incluindo esta introdução e as considerações finais. A segunda contextualiza informações sobre o histórico do programa e suas finalidades, a terceira apresenta a dinâmica de organização do programa e a quarta parte desenvolve reflexões sobre sentidos produzidos para o Paebes-Alfa, no contexto de escolas municipais.

\section{Avaliação externa na educação do Espírito Santo: experiências e ações}

A adoção da avaliação externa na educação do Espírito Santo, como política pública em larga escala, com ações sistemáticas e regulares de levantamentos de dados no contexto escolar, começou em 2008. Contudo, é importante considerar que ações anteriores, gestadas desde o ano 2000, colaboraram para essa versão recente do Programa de Avaliação da Educação Básica do Espírito Santo (Paebes). O histórico dessa trajetória pode ser compreendido a partir de fontes documentais produzidas pela Secretaria Estadual de Educação do Espírito Santo (Sedu), que registram que a proposta do programa de avaliação, inicialmente, limitava-se a "Avaliar o desempenho da rede pública estadual de ensino fundamental e médio" (Espírito Santo/Sedu, 1999, p. 13). A primeira aplicação de avaliação externa ocorreu em turmas denominadas de 


\section{pro.posições}

http://dx.doi.org/10.1590/1980-6248-2016-0011

e-ISSN 1980-6248

bloco único ${ }^{1}$. Foram aplicados dez modelos de cadernos de provas e questionários a estudantes, professores e diretores. Essa avaliação aconteceu em 12 de dezembro de 2000 e envolveu 14.423 discentes de 500 escolas estaduais urbanas e rurais, em 702 turmas, de 76 municípios, ou seja, quase a totalidade dos 78 municípios capixabas. Antes da aplicação dessa avaliação, a Sedu realizou vários eventos, como oficina de produção de itens de prova de Língua Portuguesa e Matemática para professores que atuavam no bloco único, pré-testagem desses itens em turmas dos municípios de Viana e Serra (municípios que integram a região da Grande Vitória), reunião de sensibilização da comunidade escolar sobre a importância da avaliação externa, dentre outros relacionados com a temática.

Em 2004, ocorreram aplicações de provas de Língua Portuguesa e Matemática para as turmas de $4 .^{\circ}$ e $8 .^{\circ}$ série do Ensino Fundamental da rede urbana de ensino estadual e da rede municipal de Vila Velha. Também foram avaliadas turmas de $1 .^{\circ}$ ano do Ensino Médio da rede estadual nas disciplinas Língua Portuguesa, Matemática, Química, Física e Biologia. Segundo dados da Sedu, a avaliação daquele ano atingiu 70.492 alunos da rede estadual e 3.063 da rede municipal de Vila Velha, de 617 escolas e 3.547 turmas. Essas ações mostram diferentes atividades relacionadas com a avaliação externa, porém são registradas aplicações de provas apenas em dois momentos.

A partir do ano de 2008, esse caráter pontual se modificou, pois o Paebes passou por reconfigurações e ganhou novos contornos. Esse ano pode ser considerado um marco na consolidação de ações para a qualificação e a ampliação da avaliação externa no Espírito Santo. Com a finalidade de aprimorar a sistemática de avaliação, a Secretaria Estadual de Educação firmou parcerias com várias instituições, dentre elas - e a mais duradoura - a Universidade Federal de Juiz de Fora (UFJF), representada pelo Centro de Políticas Públicas e Avaliação em Educação (Caed). Essa parceria, iniciada em 2009, foi renovada em 2012 e continuou ativa em 2015. Por meio do Caed, o programa realizou ações anuais de levantamento de dados sobre as aprendizagens dos estudantes das redes públicas (estadual e municipal) e também de escolas particulares que firmaram convênio de cooperação técnica. O público-alvo das avaliações do

\footnotetext{
${ }^{1}$ Conforme podemos ler em Dias (2013), o termo "bloco único" designa projeto que propôs a reorganização dos "dois primeiros anos do ensino fundamental das escolas públicas estaduais e municipais do Espírito Santo, eliminando a retenção - reprovação - na primeira série, com o objetivo de garantir dois anos para a alfabetização das crianças" (p. 12).
} 


\section{pro.posições}

$e$-ISSN 1980-6248

http://dx.doi.org/10.1590/1980-6248-2016-0011

programa são alunos matriculados no $5 .^{\circ}$ ano e 9. ${ }^{\circ}$ ano do Ensino Fundamental, bem como alunos do 3. ${ }^{\circ}$ ano do Ensino Médio.

No campo da alfabetização, o programa assumiu características específicas e, como informamos, é denominado de Paebes-Alfa. Tem por finalidade avaliar aprendizagens das crianças matriculadas em turmas do ciclo de alfabetização $\left(1 .^{\circ}, 2^{\circ}\right.$ e $3 .^{\circ}$ ano) nas áreas de Língua Portuguesa e Matemática. Em turmas de $10^{\circ}$ ano, são aplicadas duas avaliações. A primeira, denominada avaliação de entrada ou primeira onda, ocorre, geralmente, no primeiro trimestre letivo. Conforme documentos orientadores do programa, essa primeira avaliação visa a diagnosticar os conhecimentos prévios das crianças em Leitura, Escrita e Matemática. A segunda avaliação, denominada de saída ou segunda onda, tem o intuito de avaliar aprendizagens dos alunos a partir do processo de ensino e, comumente, é aplicada no terceiro trimestre. Em turmas de $2 .^{\circ}$ e $3 .^{\circ}$ ano, segundo informam documentos do programa, são realizadas somente as avaliações de saída para identificar a evolução das aprendizagens das crianças e produzir informações que possam subsidiar intervenções pedagógicas.

Em levantamento realizado no período entre 2008 e 2012, que se refere à primeira fase de atuação do Caed no contexto das ações do Paebes-Alfa, constatamos aumento significativo de municípios participantes. No primeiro ano, apenas 5 fizeram adesão ao Paebes-Alfa. Contudo, em 2012, 75 municípios firmaram convênio de cooperação técnica com a Sedu/ES. Em termos da rede privada, o programa agregou entre 23 e 29 escolas no período de 2010 a 2012. Esses dados mostram que a avaliação do Paebes-Alfa atinge quase todos os sistemas municipais de educação do Espírito Santo, que totalizam 78. Também demonstram que o Paebes-Alfa acontece em grande número de classes de alfabetização e, portanto, envolve expressivo contingente de crianças e profissionais das escolas. Para ilustrar a abrangência do programa, tomamos como referência os números de 2012 (Tabela 1). 


\section{pro.posições}

http://dx.doi.org/10.1590/1980-6248-2016-0011

e-ISSN 1980-6248

Tabela 1 - Número de avaliações do Paebes-Alfa aplicadas no ano de 2012

\begin{tabular}{|c|c|c|c|c|c|c|}
\hline $\begin{array}{c}\text { Ano } \\
\mathbf{2 0 1 2}\end{array}$ & \multicolumn{2}{|c|}{ Rede Estadual } & \multicolumn{2}{c|}{ Rede Municipal } & \multicolumn{2}{c|}{$\begin{array}{c}\text { Escolas Particulares } \\
\text { Participantes }\end{array}$} \\
\hline & $1^{\mathrm{a}}$ onda & $2^{\mathrm{a}}$ onda & $1^{\mathrm{a}}$ onda & $2^{\mathrm{a}}$ onda & $1^{\mathrm{a}}$ onda & $2^{\mathrm{a}}$ onda \\
\hline $\mathbf{1}^{\mathbf{o}}$ ano & 7.308 & 7.425 & 30.073 & 30.192 & 942 & 1.019 \\
\hline $\mathbf{2}^{\mathbf{o}}$ ano & - & 8.560 & - & 32.214 & - & 923 \\
\hline $\mathbf{3}^{\mathbf{o}}$ ano & - & 8.622 & - & 37.503 & - & 844 \\
\hline
\end{tabular}

Fonte: $\mathrm{Caed}^{2}$. Elaboração das autoras.

Esses números (Tabela 1) apontam que o público mais afetado pelas avaliações do Paebes-Alfa pertence às redes municipais, pois, no ano de 2012, o programa aplicou testes a cerca de 100.000 crianças entre 6 e 8 anos de idade, matriculadas em escolas municipais. Esses números evidenciam que a base de dados do Paebes-Alfa é composta prioritariamente com informações sobre a educação ofertada pelos municípios, embora o programa seja exclusivamente patrocinado, em termos de seus recursos financeiros, pelo governo estadual. Diante dessas diferenças entre quem fornece os dados e quem promove a gestão do programa, podemos indagar: Como o programa funciona no contexto dos municípios? Como ocorre a participação dos municípios e dos sujeitos das escolas (crianças e profissionais)? Que sentidos são produzidos para essa avaliação no contexto das unidades de ensino? Nos próximos tópicos, exploraremos e desenvolveremos análises sobre essas questões.

\section{Avaliação externa da alfabetização em municípios capixabas}

Para conhecer e entender as ações e as repercussões do Paebes-Alfa em redes ou sistemas públicos municipais de educação do Espírito Santo, por meio de pesquisa qualitativa do tipo estudo de caso, acompanhamos um ciclo completo de ações do programa realizado no ano de 2012, em um dos cinco municípios com maior número de matrículas e de tempo de adesão ao Paebes-Alfa, ou seja, com vinculação desde o ano de 2008. Esse município integra a região metropolitana da Grande Vitória, e sua rede de ensino possui majoritariamente escolas urbanas, exceto algumas poucas unidades classificadas como rurais.

\footnotetext{
${ }^{2}$ Dados apresentados pela equipe do Caed em reunião de divulgação dos resultados das avaliações do Paebes e do Paebes-Alfa de 2012. Esse evento ocorreu em 27 de março de 2013, na cidade de Vitória/ES.
} 


\section{pro.posıções}

$e$-ISSN 1980-6248

http://dx.doi.org/10.1590/1980-6248-2016-0011

A escolha por essa metodologia de pesquisa (estudo de caso) encontra fundamentos nas proposições de Sarmento (2003, p. 137) que, em diálogo com Merriam (1988), define que esse tipo de pesquisa se caracteriza, especificamente, por focalizar "fenômeno específico, tal como um programa, um acontecimento, uma pessoa, um processo, uma instituição, ou um grupo social” (p. 9). Neste texto, analisamos os sentidos produzidos por sujeitos pertencentes a um sistema público de ensino envolvidos no Paebes-Alfa, programa de avaliação da alfabetização do Espírito Santo.

Realçamos que o ano de 2012, período em que ocorreu o trabalho de campo da pesquisa, pode ser considerado representativo no contexto do Paebes-Alfa, porque foi o ano de conclusão do primeiro contrato de parceria entre Sedu e Caed. Desse modo, sistematizava-se um período de quatro anos de levantamentos regulares de dados produzidos por avaliação externa na alfabetização do Espírito Santo.

O acompanhamento das atividades do Paebes-Alfa, nesse referido ano, foi realizado com base na participação de umas das autoras deste artigo, na condição de pesquisadora, em eventos $^{3}$ realizados pela Sedu/Caed. Precisamente, participamos de eventos de divulgação dos resultados das avaliações aplicadas em 2011, de ações preparatórias para aplicação das provas do ano de 2012, de aplicação de provas em 11 salas de aula de alfabetização e também de divulgação dos resultados das avaliações de 2012, publicado em evento oficial da Sedu/ES, no ano de 2013.

Além dessas ações, acompanhamos encontros de formação continuada de professores alfabetizadores e reuniões pedagógicas, organizados pela gestão do município investigado. Nesses eventos, dialogamos com diferentes sujeitos envolvidos com o Paebes-Alfa e articulamos fontes diversas de dados. Os registros desses dados foram realizados por meio de gravações de áudio e vídeo dos eventos, aplicação de questionários a 111 professores alfabetizadores sobre experiências com o Paebes-Alfa, entrevistas com profissionais da gestão (estadual e municipal) do programa e também com sujeitos de 4 escolas municipais (professores, pedagogos e diretores).

\footnotetext{
${ }^{3}$ O termo "evento" é utilizado neste artigo a partir das proposições de Mikhail Bakhtin (2010), cujo texto original, produzido entre os anos de 1920-1924, é intitulado K filosofii postuplk.a.
} 


\section{pro.posıções}

$e$-ISSN 1980-6248

http://dx.doi.org/10.1590/1980-6248-2016-0011

A partir dos dados empíricos produzidos sobre o Paebes-Alfa, compreendemos a sequência de ações do programa e as repercussões no contexto escolar. Cada ciclo anual é composto por atividades de produção de dados e de divulgação de resultados da avaliação. A primeira possui uma agenda determinada pelos gestores do programa, Sedu/Caed, que especificam datas para divulgação das regras de funcionamento das avaliações, para organização e preparação das equipes locais envolvidas no trabalho de aplicação das provas, bem como determinam datas de aplicação dos exames nas salas de aula. Desse modo, o trabalho das Secretarias Municipais de Educação e das escolas é atravessado, alterado e adaptado em função da agenda de ações do Paebes-Alfa e à revelia dos sujeitos.

Essa estrutura organizacional do sistema de avaliação indica adesão a uma linha impositiva de gestão, em que os sujeitos envolvidos devem se submeter às prescrições do programa. Durante a realização do evento de divulgação das normas de funcionamento da avaliação do Paebes-Alfa, os gestores municipais do programa recebem um caderno denominado Manual do Coordenador Local. Nesse caderno, estão contidas todas as regras e o detalhamento de procedimentos que devem ser atendidos nessa avaliação. Podemos inferir que, a partir do próprio nome do documento, encontramos o reforço do sentido de prescrição, pois o termo "Manual" direciona a esse significado.

Nesse documento, são relacionadas especificações de como devem realizar os trabalhos do Paebes-Alfa o gestor municipal e os profissionais da escola, principalmente os professores alfabetizadores que atuavam como aplicadores e promoviam a produção dos dados da avaliação. Para esses, os manuais relacionavam procedimentos a adotar em sala de aula, antes da aplicação da prova, durante a prova e após a sua realização. Para ilustrar especificações dessa natureza, apresentamos alguns trechos dos manuais.

Cumprimentar os alunos e apresentar-se, dizendo seu nome.

Verificar se a sala está em ordem e se todo o material pedagógico exposto foi retirado ou coberto.

Organizar as carteiras em fila, caso não seja essa a disposição delas na sala de aula, pedindo aos alunos para se acomodarem de forma diferente à que eles ficam regularmente.

Solicitar aos alunos que deixem sobre a carteira somente o lápis e a borracha. (Secretaria Estadual de Educação, 2012 b, pp. 26-27) 


\section{pro.posıções}

$e$-ISSN 1980-6248

http://dx.doi.org/10.1590/1980-6248-2016-0011

Notamos, nesses enunciados, o aprofundamento das intenções de prescrição das ações dos sujeitos (professor e aluno). As regras determinam uma forma específica de organização e de como cada segmento deve se portar no momento da avaliação. Logo, a noção de ordem e comando perpassa todo o discurso dos manuais, de acordo com os quais os sujeitos, os monitores, os aplicadores e as crianças devem assumir atitudes passivas diante das determinações do programa. Outra mostra dessas intenções pode ser identificada quando o manual especifica o dizer dos aplicadores para o início da avaliação.

A turma fará um exercício individual de Língua Portuguesa (leitura e escrita), OU de Matemática. Guarde tudo que estiver na sua carteira. Deixe somente o lápis e a borracha [aguardar até que os alunos se organizem]. Cada um fará o exercício sozinho, do jeito que souber. Não vale olhar o do colega. Você vai mostrar tudo o que já sabe fazer. Se tiver alguma atividade que não saiba fazer, não tem problema, não precisa ficar nervoso. Você pode tentar fazê-la ou deixar em branco. Vocês devem permanecer sentados para receber os Cadernos de Testes. O Cartão de Respostas não pode ser destacado do Caderno de Testes.

Por favor, esperem um pouco que todos farão o exercício juntos. O teste terá duração total de 2 (duas) horas. (Secretaria Estadual de Educação, 2012 b, pp. 27-28)

É possível inferir, a partir desse tipo de materialidade discursiva, que há um projeto progressivo de intenções. Esse projeto se inicia com prescrições de ações, evoluindo para prescrições do dizer dos sujeitos. Nesse processo, parece que está implícita a construção de um ouvinte ideal, supostamente passivo. Segundo Bakhtin (2003), essa forma de conceber o outro é uma formação abstrata.

O ouvinte ideal é, no fundo, um reflexo especular, uma dublagem do autor. Ele não pode introduzir nada de seu, nada de novo na obra interpretada em termos ideais e nem no plano idealmente completo do autor. ... não pode ser o outro (ou um estranho) para o autor, não pode ter nenhum excedente definível pela alteridade.[ênfase no original]. Entre autor e tal ouvinte não pode haver nenhuma interação, nenhuma relação dramática ativa, porquanto eles não são vozes mas conceitos abstratos iguais a si mesmos e entre si. Aí só são possíveis abstrações tautológicas vazias, mecanicistas ou matematizadas. Aí não há um grão de personificação. (p. 405)

Essa relação desejada de passividade e subserviência do ouvinte em relação ao autor, apontada por Bakhtin (2003) nos pressupostos do conceito de ouvinte ideal, pode ser identificada recorrentemente nos manuais do Paebes-Alfa. Pensamos que os discursos veiculados por esses documentos explicitam ideias do que o outro (monitor, aplicador, criança) deve ser, dizer, agir e saber, no contexto da avaliação. Portanto, fica subentendido que os sujeitos 


\section{pro.posıções}

$e$-ISSN 1980-6248

http://dx.doi.org/10.1590/1980-6248-2016-0011

não podem alterar ou interferir nas proposições; eles apenas devem assimilar e executar orientações, padronizadas, muitas vezes incompatíveis com a dinâmica da sala de aula e as especificidades das crianças em fase de alfabetização, como podemos conferir a seguir:

O verbo DIZER apresenta a instrução que será dada. É o comando do item e por isso deve ser lido com uma velocidade adequada (nem rápido demais, nem muito lentamente), com boa pronúncia. Se a criança não entender, a instrução pode ser repetida, uma única vez, da mesma maneira. (Secretaria Estadual de Educação, 2012 a, p. 25)

Observamos que as recomendações enfatizam aspectos técnicos da avaliação e abstraem complexidades e especificidades que normalmente atravessam o contexto das salas de aula e dos sujeitos. Esses discursos eram propagados em cadeia verticalizada, pois os gestores municipais eram responsáveis por promover encontros de divulgação das orientações para as provas, com a equipe de profissionais da Secretaria de Educação local e também com os gestores das escolas (pedagogos e diretores). Esses, por sua vez, deveriam assumir a tarefa de repassar aos professores, que tinham a função de transformar discursos em práticas, ou seja, efetivar o processo de produção dos dados da avaliação no contexto da sala de aula. Essa trajetória de ações do programa indica uma concepção de sujeito obediente, que pressupõe o cumprimento das determinações. Mas como esse processo acontece no contexto das escolas? E das salas de aula?

\section{Avaliação externa da alfabetização em escolas municipais: sentidos possíveis para o Paebes-Alfa}

O desenvolvimento de avaliações do Paebes-Alfa no contexto escolar oferece elementos para a produção de sentidos variados pelos sujeitos participantes. Dentre eles, podemos identificar que essa avaliação produz, nos profissionais e nas crianças, o sentido do incômodo, especialmente, por provocar alteração da rotina dos trabalhos da escola/sala de aula. Esse sentido específico pode ser confirmado pelas exigências do programa para a aplicação dos testes, como a troca de professores das turmas e a intervenção no espaço físico, pela retirada de cartazes ou de qualquer tipo de informação visual que as crianças possam consultar. Além dessas evidências, é possível notar essa alteração pela presença de um profissional da equipe da 


\section{pro.posıções}

$e$-ISSN 1980-6248

http://dx.doi.org/10.1590/1980-6248-2016-0011

Secretaria Municipal de Educação presente na escola para atuar como monitor e assumir a responsabilidade de acompanhar e garantir o cumprimento das normas do programa.

Esse modo de organização do Paebes-Alfa, na fase de produção dos dados, indica a força e a personificação do discurso estrangeiro, formulado em instância privada que invade a escola e ocupa o lugar do oficial, do Estado. Essa afirmação parte do entendimento de que o Caed, como órgão de natureza público-privada, no momento de aplicação das provas, determina o funcionamento do espaço público, ou seja, formula abstratamente enunciados que prescrevem como a escola e as salas de aula devem funcionar. Sobre esse momento de alteração da rotina escolar, uma das professoras participantes da pesquisa afirmou que o Paebes-Alfa

entra e depois vai embora... a gente começa com outras situações na sala de aula... não é uma coisa que fica... é um movimento que assopra... tira todo mundo do lugar... gera aquele desconforto ... mas depois volta a nossa rotina... do dia a dia. (Professora Júlia ${ }^{4}$, Diário de Campo, 28-6-2012) ${ }^{5}$

Outra professora, durante encontro de formação continuada, também manifestou percepções na direção do que observa a professora Júlia. Ela disse:

A Secretaria (de educação) vem com cobranças e a escola também. Agora vamos ter o Paebes-Alfa. A cobrança já está na $1^{a}$ onda. Isso não é uma onda, é uma tsunami. Ensinar menino margem, marcar $x$. Vocês cobram (Secretaria) como se fosse 1. a série. Colocar um atrás do outro é um absurdo. (Diário de Campo, 9-4-2012)

Esses excertos indicam como o Paebes-Alfa é percebido pelos professores quando chega à sala de aula, a partir dos eventos de aplicação das avaliações. Além dos professores, as crianças, nessas ocasiões de realização das provas, enfrentavam situações de incômodo e desconforto. Em entrevista com os diretores das escolas, eles disseram que informavam as famílias sobre a data do teste e advertiam as crianças para não faltarem, pois a sua ausência prejudicaria o índice de participação das escolas na avaliação. Uma das quatro diretoras entrevistadas relatou que costumava não avisar as famílias e os alunos sobre a previsão da ocorrência da prova, pois considerava que esse tipo de comunicado poderia gerar ausências intencionais. Esses procedimentos adotados pelas diretoras e pela equipe escolar indiciam

\footnotetext{
${ }^{4}$ Os nomes dos sujeitos são fictícios, atendendo ao preceito ético de pesquisa com seres humanos no quesito de preservação da identidade dos participantes do estudo.

${ }^{5} \mathrm{O}$ trabalho de transcrição de textos orais produzidos na pesquisa tomou como referência as normas propostas por Fávero, Andrade e Aquino (2005).
} 


\section{pro.posıções}

http://dx.doi.org/10.1590/1980-6248-2016-0011

\section{$e$-ISSN 1980-6248}

respostas às pressões oriundas do Paebes-Alfa, seja para o alcance de índices de participação, seja para o alcance de níveis de acertos às questões.

É possível pensar ainda que esses procedimentos pressupõem relações de poder desiguais. Nessas situações, as crianças são consideradas sujeitos controláveis, sem voz, submetidas à autoridade do adulto, que lhes impõe e determina a obrigação de realizar a avaliação externa. Em termos éticos, remete-nos ao conceito de criança subserviente, calada, obediente, destituída de direitos básicos, como o de manifestar desejos e opiniões, de apresentar questionamentos, de posicionar-se criticamente diante de uma situação vivida, enfim, de ser ouvida. Cabe supor que uma perspectiva reduzida de conceber o conceito de criança subsidia a consolidação de uma cultura de avaliação em longo prazo, pois talvez assim, no futuro, os adolescentes venham a ser mais receptivos às avaliações externas, o que pode justificar também mais uma razão para a precocidade dessas avaliações no contexto da alfabetização.

Além desses movimentos e dessas ações prévias de organização das escolas, o acontecimento da avaliação do Paebes-Alfa, em sala de aula, mostra que os discursos prescritivos são interpretados/encenados no âmbito da vida na escola de diferentes modos. Vemos que esses discursos comportam um limiar, uma fronteira, que é potencialmente penetrável pelos discursos produzidos pelos sujeitos da sala de aula, colocando em evidência a natureza discursiva, dialógica, e o seu inacabamento. Para indicar esse inacabamento, escolhemos alguns extratos discursivos produzidos por professores aplicadores e por crianças no acontecimento de avaliações do Paebes-Alfa em sala de aula, para demonstrar que os sujeitos que habitam esse espaço-tempo interpretam e encenam esses discursos de outra forma, pois se localizam em outro lugar (Petrilli, 2013).

Embora possamos apreender, no conjunto dos enunciados que compõem os instrumentos do Paebes-Alfa, uma noção de objetividade e padronização, registramos que uma mesma questão da prova pode ser orientada/explicada de forma específica, singular, em função dos contextos e dos sujeitos. Para ilustrar, apresentamos enunciados referentes à questãoexemplo da prova da 2. onda de 2012. Essa questão tinha por objetivo mostrar às crianças o modo de funcionamento da avaliação, sendo idêntica nas turmas acompanhadas em nossa investigação. O item consistia na apresentação da figura de uma chave, e as crianças deveriam registrar um X na opção em que estava escrito o nome da figura. 


\section{pro.posıções}

$e$-ISSN 1980-6248

Professora Aplicadora: todo mundo já abriu na chave... isso... na chave... então vamos lá... observe a figura... qual é o nome dessa figura... aqui embaixo... tem um monte de nominho... você só vai marcar o x... onde está escrito o nome dessa figura... aí tem... chalé... chave... xadrez... xale... (faz a leitura na sequência dos itens apresentados na questão) onde está escrito o nome dessa figura aqui no quadradinho? marca o x... no seu quadradinho... aí no seu caderno... vamos lá... só onde está escrito a palavra no seu quadradinho...

Criança: onde, tia?

Professora Aplicadora: não sei... cha-ve... (aponta para o desenho da prova) cha - ve - ve - ve... CHA:.:.: VE:..:. ...por que o seu caderno está fechado? já fez? (fala para um menino) não fecha não... deixa ele aberto... prestem atenção... CHA::::VE::.:. ...onde está escrito essa palavra aqui? lê a primeira palavrinha... o que está escrito na primeira palavrinha? ai você lê a segunda palavrinha... é pra ler... vamos lá... vamos ler no caderninho... vamos descobrir onde está escrito chave... vamos lá...

Criança: eu achei...

Professora Aplicadora: isso... quem achou... marque o x... só marque o $x$ se achou a palavra cha:::ve:.: todo mundo já marcou? virou a folbinha... essa aqui agora... (mostra o segundo cartaz) (Aplicação da prova do Paebes-Alfa na Escola Litoral, 1 ano, Diário de Campo, 6-11-2012).

Professora Aplicadora: olha só... veja a figura abaixo... veja a figura aB AIxo... e ai ninguém vai falar alto... você vai pensar pra você... vai falar só pra você... bem baixinho... aqui dentro do pensamento (coloca o dedo indicador na testa)... olha aqui... tem quatro quadradinhos... um... dois... três... quatro... na frente de cada quadradinho... é uma palavra...

Crianças: (algumas crianças levantam e conversam enquanto a professora explica)

Professora Aplicadora: (ao observar a movimentação dos alunos, abre a porta e diz) a:::ssim não dá... espera aí... eu vou chamar a professora lá... da Sedu (faz referência ao profissional da Secretaria de Educação que monitora a aplicação)... porque vai ter que ser retirado... só os dois que não estão se comportando direito... o que é que eu falei? é para poder ir na mesa do colega agora? então vamos lá... o que você irá faẓer... você vai ouvir... vai pensar... vai ler pra descobrir qual é a resposta... e vai marcar a resposta... somente uma resposta é a certa... então... qual é o nome dessa figura?

Criança: chave... (pronuncia em voz alta)

Professora Aplicadora: psiu::::::

Criança: chave... (outra criança também verbaliza)

Professora Aplicadora: ninguém vai falar nada...

Criança: eu sei tia... chave... 


\section{pro.posıções}

$e$-ISSN 1980-6248

http://dx.doi.org/10.1590/1980-6248-2016-0011

Professora Aplicadora: ei... você ouviu o que eu falei? que não pode falar a resposta agora? cada um vai faz̨er o seu... SOzinho... e cada um vai marcar a resposta que acha que é... ... primeiro ano... isso aqui é só um exemplo... vocês já fizeram da outra vez... vocês já sabem como é... não precisa chamar a tia pra ver... não precisa... pensa um pouquinho... e marca... olha só... tem quatro palavrinhas... em uma dessas tá escrito ch.:... tá escrito o nome do desenho... eu também não posso falar o nome do desenho... não posso... ... eu só posso ler pra você veja a figura abaixo... você vai ver... vai observar... e então eu li para você... qual o nome dessa figura... só isso... e aí você marca o nome da figura... o nome do desenho...

Criança: tia, é a chave...

Professora Aplicadora: ele entendeu né... que não pode falar nada (ironicamente)... (Aplicação da prova do Paebes-Alfa na Escola Serra, 1. ${ }^{\circ}$ ano, Diário de Campo, 6-11-2012).

As sequências discursivas indicam que profissionais e crianças realizam procedimentos distintos. Evidenciam que o processo de compreensão das regras do programa na arena, sala de aula, é criativo e produtivo, pois os sujeitos não se limitam à repetição das palavras especificadas nas orientações da prova, ou seja, não assumem o papel de ouvinte ideal (Bakhtin, 2003), que obedece literalmente às instruções. Assim, indicam que a compreensão humana comporta contrapalavras e, como nos afirma Geraldi (2013), os sujeitos levam adiante e para frente aquilo que entenderam.

Nesse sentido, noções de objetividade, isenção e individualidade, que em geral marcam o processo de coleta de dados em avaliações externas e em larga escala, como é o caso do Paebes-Alfa, podem ser problematizadas e relativizadas, quando em avaliações realizadas com crianças do ciclo de alfabetização. Esse entendimento parte especialmente de registros de atitudes responsivas das crianças, manifestadas durante eventos de aplicação dos testes, pois muitas desconsideravam a lógica proposta e conversavam entre si, trocavam informações, verbalizavam respostas dos itens, ou ainda escolhiam aleatoriamente respostas, sem observar as instruções dos aplicadores. Essas atitudes das crianças mostram especificidades da infância e distanciamentos com a dinâmica orientadora desse tipo de avaliação. O conhecimento das práticas efetivadas em sala de aula, no momento da avaliação do Paebes-Alfa, sinaliza aos gestores do programa limites para entender os resultados como expressão direta de níveis de aprendizagem individual.

Avaliações do Paebes-Alfa possuem também potencial para consolidar práticas de silenciamento de vozes. O desenvolvimento desse sentido encontra fundamentos a partir de elementos inerentes a concepções de leitura e de escrita que sustentam itens que compõem essa 


\section{pro.posıções}

$e$-ISSN 1980-6248

avaliação. Nessa direção, passamos a expor evidências discursivas registradas em eventos de aplicação das provas do programa, que julgamos confirmar nossa assertiva.

Professora Aplicadora: questão número oito... VEja as figuras... veja as figuras...

Criança: eu já vi as figuras...

(vozes)

Criança: coruja... tartaruga... jacaré...

Professora Aplicadora: barata... coruja... tartaruga... jacaré...

Crianças: (verbalizam o nome das figuras concomitantemente)

Criança: ô tia... isso é um crocodilo...

Professora Aplicadora: JA-CA-RÉ

Criança: é crocodilo...

Professora Aplicadora: psiu... então veja as figuras... barata... coruja... tartaruga...

[

Crianças: crocodilo...

[

Professora Aplicadora: e jacaré... (Aplicação da prova do Paebes-Alfa na Escola Serra, $1 .^{\circ} \cdot$ ano, Diário de Campo, 6-11-2012).

Professora Aplicadora: vamos lá... questão dezenove... por que as flores têm espinhos? por que as flores têm espinhos? (título do texto do item)

Criança: pra ninguém pegar nelas... 


\section{pro.posıções}

$e$-ISSN 1980-6248

http://dx.doi.org/10.1590/1980-6248-2016-0011

Professora Aplicadora: o espi:::nho é uma folha diferente... e pontiaguda... ele protege as plantas... (realiza a leitura do texto integrante do item)

(Aplicação da prova do Paebes-Alfa na Escola Litoral, 1. · ano, Diário de Campo, 6-11-2012).

Esses extratos explicitam que o leitor deve apreender determinado significado e que suas possíveis compreensões e/ou conhecimentos não entram em jogo no processo de interação com o texto. Assim, a noção da criança sobre a possibilidade de o desenho significar um crocodilo e não um jacaré não é passível de discussão, pois já está definido que o desenho deve ser entendido apenas como jacaré. No segundo exemplo, quando a criança, a partir da pergunta "por que as flores têm espinhos?", formulou a resposta que era "pra ninguém pegar nelas", provavelmente estava fazendo referência a alguma experiência e/ou conhecimento relacionado com tal questão. Contudo, isso não era importante no momento da avaliação, pois a pergunta do item queria saber apenas o assunto do texto, ou seja, a criança devia reiterar a própria pergunta e não a ela responder.

Essa abordagem da leitura nos testes do Paebes-Alfa era uma constante no conjunto dos itens. Quando analisamos questões que utilizavam textos, em versões de provas aplicadas em 2012, verificamos que as finalidades anunciadas para a leitura envolviam identificar o assunto, o gênero, as informações explícitas ou significado de palavras ou expressões ali contidas. Sendo assim, o conceito de texto é tomado como autoridade do conhecimento, porque contém as respostas corretas. Ao leitor, cabe apenas fazer a identificação e a reiteração dessas informações.

Esse tipo de orientação epistemológica apresenta limitações, pois compreendemos a leitura como atividade dialógica, em que leitor e autor se encontram no texto. Nessa interação, o leitor chega carregado de contrapalavras para participar do diálogo. Assume posição ativa e responsiva, na qual tem possibilidade de inferir informações, relacionar ideias e outros textos, discordar, concordar - enfim, por meio da leitura, ele se posiciona como sujeito pensante e tem a possibilidade de produzir/tecer novos textos, como indicam as enunciações das crianças nos extratos discursivos apresentados.

Em relação à escrita, o programa segue essa mesma linha de proposição indicada em ítens de leitura. Para avaliar as capacidades das crianças, os testes contemplavam escrita de palavras, frases e textos, a partir de ditado ou imagens. Esse modo de conceber a escrita não 


\section{pro.posıções}

$e$-ISSN 1980-6248

http://dx.doi.org/10.1590/1980-6248-2016-0011

possibilita às crianças encontrar condições favoráveis para produzir enunciados plenos, pois o roteiro do que deve ser registrado está previamente determinado pelas imagens ou pelo ditado, bem como pela forma como deve ser registrado, uma vez que a definição do gênero textual também é apontada nas instruções dos itens.

$\mathrm{Na}$ produção de texto a partir de imagens, a escrita funciona como ilustração, e a criança deve demonstrar saber registrar por escrito o seu conteúdo, de forma ortograficamente correta, pois há um interlocutor previsto que, nesse caso, é um avaliador. Assim, a criança sabe que, para esse interlocutor, mesmo distante e desconhecido, é importante demonstrar que ela domina a escrita correta, conforme podemos entrever nos excertos a seguir:

Professora Aplicadora: olha só... observe a figura... bom... qual o nome dessa figura?

Crianças: $p i-p a($ em coro)

Professora Aplicadora: então... nós conhecemos esse brinquedo chamado como... pipa... mas aqui na atividade... trouxe o nome dele de papagaio...

Criança: papagaio...

[

Criança: mas não é...

[

Professora Aplicadora: então ele também é chamado de papagaio... esse brinquedo... então escreva o nome desta figura...

Criança: papagaio? eu não sei...

[

Criança: épipa...

Criança: tia... tem que escrever esse nome que você falou... na linha?

Professora Aplicadora: é::... 


\section{pro.posıções}

$e$-ISSN 1980-6248

Crianças: ah:..... não... (crianças reclamam e se recusam a escrever a palavra papagaio)

(vozes)

Professora Aplicadora: faz assim... olha só... escreva o nome do desenho... o nome que você conhece... né... você conhece esse brinquedo como?

Crianças: pipa (em coro) (Aplicação da prova do Paebes-Alfa na Escola Serra, 1· ano, Diário de Campo, 24-4-2012).

Professora Aplicadora: todo mundo nessa página aqui ((mostra o cartaz))... que figura é essa? não falam... não pode falar..

Criança: eu sei, tia...

Professora Aplicadora: escreva o nome dessa figura... na linha... você vai escrever o nome dessa figura...

Criança: de qualquer jeito, tia...

Professora Aplicadora: de qualquer jeito não... você vai escrever... escrevendo... que figura é essa? começa com que letra? você vai escrever o nome da figura... não é de qualquer jeito...

Criança: rosa... tia?

Criança: tia... mas eu não sei escrever...

Professora Aplicadora: tá... mas que figura é essa? fala pra tia... que figura é essa?

Criança: uma planta...

Professora Aplicadora: uma flor... FLO:.:.:R:....... flor... como que se escreve?

Criança: flor...

Professora Aplicadora: então escreve... cada um vai, escreve do jeitinho que... SA:::BE::....

Criança: tia... mas eu não sei não... 


\section{pro.posıções}

$e$-ISSN 1980-6248

http://dx.doi.org/10.1590/1980-6248-2016-0011

Professora Aplicadora: flor... flo:::r::.... cada um vai escrever do jeitinho que sabe... por isso que não pode olhar para o do colega (Aplicação da prova do Paebes-Alfa na Escola Litoral, 1. ${ }^{\circ}$. ano, Diário de Campo, 6-11-2012).

Nos dois extratos, podemos perceber que as crianças conheciam outras denominações para as figuras apresentadas. Entretanto, considerando as bases de caráter experimental que sustentam a elaboração e a correção dos itens do teste e a sua finalidade de controle da aprendizagem, a multiplicidade de palavras não é relevante. A palavra de um outro, um estrangeiro, impõe-se sobre a linguagem dos sujeitos. Desse modo, o item exige das crianças uma resposta que não tem origem no seu contexto linguístico real.

Bakhtin e Volochínov (2004) assinalam, em Marxismo e filosofia da linguagem, o lugar que a palavra estrangeira "desempenhou no processo de formação de todas as civilizações da história" (p. 101). Para eles, a palavra estrangeira "foi, efetivamente, o veículo da civilização" (p. 101) e, nesse sentido, ela, que se impõe aos sujeitos dominados, se funde "à ideia de poder, de força, de santidade, de verdade" (p. 101). Na situação do teste, a palavra estrangeira se impôs como forma correta, o que levou as crianças a pensar que ela e toda a sua comunidade falavam errado ou denominavam erradamente as figuras.

Obviamente, isso tem repercussões sobre as crianças e as silencia. Essa prática de avaliação se mostra, desse modo, autoritária, pois produz o silenciamento das vozes dos sujeitos e, como assinala Geraldi (2010) em outro contexto analítico, ao mesmo tempo em que " silencia, faz retornar a ordem" (p. 114), pois, assim como a polissemia de significados, a variedade de palavras produz o caos, impossibilitando a mensuração pelas máquinas elaboradoras e corretoras de testes que, apesar de humanas, perderam toda a sensibilidade e, por isso mesmo, não desconfiam que escravizam e silenciam as crianças.

Assim, o avaliador, ao definir uma única resposta para o item que pode ter diferentes respostas, parece partilhar de uma perspectiva de linguagem como um sistema estático de códigos em que a relação significante e significado é determinada a priori. Nessa acepção, as crianças obrigadas a se submeter a esse tipo de avaliação são tomadas como passivas, devem demonstrar de forma objetiva o domínio dos aspectos estáveis da língua. Porém, na prática viva da língua, e como as respostas das crianças inicialmente demonstraram, as palavras de uma língua são compreendidas em relação com o contexto concreto e preciso de vivências coletivas de uma comunidade linguística. 


\section{pro.posições}

e-ISSN 1980-6248

http://dx.doi.org/10.1590/1980-6248-2016-0011

A partir das contribuições de Bakhtin e Volochínov (2004), podemos deduzir que itens dessa natureza, que pretendem avaliar o domínio da capacidade de escrita das crianças, podem ser considerados potencialmente formas de exercício de poder sobre os outros mais fracos e menores, pois inibem o dizer das crianças e determinam uma única escrita correta, válida. Isso posto, uma avaliação desse tipo pode ser entendida como uma estratégia autoritária, racional e classificatória que submete os sujeitos (professores e crianças) a determinadas condições e relações com o conhecimento da língua. Essas condições não necessariamente estão comprometidas em apreender o potencial humano no campo da linguagem, mas se limitam a apurar índices ou não de certos aspectos homogêneos da língua pelos sujeitos.

\section{Considerações finais}

Concluímos este artigo, sinalizando que a compreensão do processo de produção de sentidos do Paebes-Alfa necessita dialogar com diferentes fontes. Elas vão desde o conteúdo discursivo de documentos orientadores do programa, que apontam em que consiste essa avaliação no âmbito dos textos primários, até práticas sociais que integram o efetivo acontecimento dessa avaliação externa em sala de aula.

Acreditamos que as discussões apresentadas ao longo do texto mostram que, quando nos aproximamos dos atos-eventos da avaliação do Paebes-Alfa, efetivados no contexto das escolas, ampliamos nosso olhar, pois observamos que os discursos prescritivos, materializados em documentos do programa, são encenados de forma singular nos espaços-tempos da sala de aula. A aridez da palavra, marcada inicialmente pela racionalidade técnica dos documentos, quando entra na arena das práticas discursivas de professores e crianças, ganha novos contornos e tons apreciativos que rompem o limiar da palavra prescrita e apontam o horizonte do seu inacabamento.

Entendemos também que o modo de tratar os conhecimentos da leitura e da escrita na avaliação do Paebes-Alfa, com prioridade para reflexões sobre unidades menores da língua, bem como a concepção de produção de texto, que privilegia a reiteração de roteiros determinados, evidencia vinculações com pressupostos da concepção de linguagem, denominada por Bakhtin e Volochínov (2004, 2013) de “objetivista abstrata”. Nessa concepção, 


\section{pro.posições}

$e$-ISSN 1980-6248

http://dx.doi.org/10.1590/1980-6248-2016-0011

a língua como sistema de formas normativamente idênticas é uma abstração que pode ser justificada teórica e praticamente somente quando se tem em vista a decodificação e o ensino de uma língua estrangeira morta. Este sistema não pode servir de base para a compreensão e explicação dos fatos linguísticos vivos e em formação. Ao contrário, distancia-se da realidade viva, dinâmica da língua e de seu funcionamento social, não obstante os defensores do objetivismo abstrato reivindicarem para sua teoria um significado social. $\mathrm{Na}$ base teórica do objetivismo abstrato estão os pressupostos de uma visão de mundo racionalista e mecanicista que são incapazes de dar uma base correta à compreensão da história, enquanto, ao contrário disso, a língua é um fenômeno exclusivamente histórico. (p. 124) ${ }^{6}$

Quando Bakhtin e Volochínov (2004) afirmam que o objetivismo abstrato está baseado numa visão racionalista e mecanicista, indicam que muitas outras dimensões da linguagem não são exploradas por essa abordagem. Na avaliação do Paebes-Alfa, observamos essas ausências, especialmente no que se refere aos conhecimentos da dimensão discursiva do processo de alfabetização. Conhecimentos que julgamos essenciais ao domínio pleno da língua materna e que podem constituir instrumento de potencialização de vozes, fundamentais a uma formação cidadã.

Finalizamos este artigo, acreditando que os dados apresentados demonstram que a qualidade da alfabetização produzida e veiculada por meio dos índices do Paebes-Alfa pode ser considerada restrita, rudimentar, pois explora conhecimentos apenas da dimensão linguística. Essa dimensão, nos testes aplicados em quase todas as salas de aula da rede pública, mostra ou exemplifica para professores e crianças da classe popular o que é importante ensinar e aprender na alfabetização. Assim, pensamos que essa política induz, valoriza ou reforça tradicionais práticas de alfabetização que, historicamente, não foram capazes de democratizar a cultura escrita. Portanto, é possível afirmar que a política de avaliação externa Paebes-Alfa segue tendências de outras avaliações externas, pois objetiva avaliar a língua como sistema pronto, o que indica empobrecimento de experiências escolares pela ênfase em questões abstratas e desconsideração de aspectos de discursividade.

Realçamos que partilhamos da defesa da qualidade da alfabetização para todas as crianças, porém qualidade pensada numa perspectiva ampla e negociada por diferentes vozes, em especial, com a participação dos sujeitos envolvidos diretamente no processo, para que eles possam enunciar demandas e necessidades a partir da complexidade da vida na escola. Qualidade

\footnotetext{
${ }^{6}$ Essa obra apresenta traduções de uma coletânea de textos produzidos por Voloschínov no período entre 1925 a 1930.
} 


\section{pro.posıções}

$e$-ISSN 1980-6248

http://dx.doi.org/10.1590/1980-6248-2016-0011

pensada para além da restrita vinculação com resultados de provas objetivas, pois, conforme Esteban (2008) explica, esse tipo de relação direta, uniforme, guarda contradições importantes e muitas vezes antidemocráticas.

Reconhecemos que a área da avaliação integra discussões diversas, constitui campo de conflitos, disputas e interesses, contudo, nos situamos no contexto de discussão que concebe a avaliação para além da lógica da auditoria, do controle verticalizado, das políticas de meritocracia. Assim nos inserimos nesse debate em diálogo com autores como Esteban (2008, 2012), Freitas (2005, 2012, 2013), Gontijo (2013), Mortatti (2013) e muitas outras vozes que conversam com os sujeitos da escola. 


\section{pro.posıções}

$e$-ISSN 1980-6248

http://dx.doi.org/10.1590/1980-6248-2016-0011

\section{Referências}

Azevedo, J. M. L. de. (2011, setembro/dezembro). Notas sobre a análise da gestão da educação e da qualidade do ensino no contexto das políticas educativas. Revista Brasileira de Política e Administração da Educação, 3(27), 361-588. Retirado em 2 de agosto de 2013, de $<$ http://seer.ufrgs.br/rbpae/issue/view/1587/showToc>.

Bakhtin M. (2003). Estética da criação verbal. São Paulo: Martins Fontes.

Bakhtin M., \& Volochínov (2004). Marxismo e filosofia da linguagem. São Paulo: Hucitec.

Bauer, A. (2010, maio/agosto). Usos dos resultados das avaliações de sistemas educacionais: iniciativas em curso em alguns países da América. Revista Brasileira de Estudos Pedagógicos, 228(91), 315-344.

Brooke, N., Cunha, M. A. A., \& Faleiros, M. (2011). Avaliaģão externa como instrumento da gestão educacional nos estados (Relatório de pesquisa). Game/Fae/UFMG apoio Fundação Victor Civita. Retirado em 4 de outubro de 2012, de < http://www.fvc.org.br/pdf/livro2-01avaliacao.pdf $>$.

Cabrito, B. G. (2006, maio/agosto). Avaliar a qualidade em educação: avaliar o quê? Avaliar como? Avaliar para quê? Cadernos Cedes, 78(29), 178-200. Retirado em 1 de agosto de 2013, de <http://www.cedes.unicamp.br>.

Casassus, J. (2009). Uma nota crítica sobre avaliação estandardizada: a perda da qualidade e a segmentação social. Sísifo. Revista de Ciências da Educação, 9, 71-78. Retirado em 2 de agosto de 2013, de <http://sisifo.fpce.ul.pt. >.

Dias, F. P. O. (2013). O bloco único no município da Serra: contribuições à bistória e à política de alfabetização - 1995-2013. Dissertação de Mestrado em Educação, Programa de PósGraduação em Educação, Universidade Federal do Espírito Santo, Vitória-ES.

Espírito Santo. Secretaria de Estado da Educação. (1999). Gerência de Qualidade da Informação e da Avaliação. Programa de Avaliação da Educação Básica do Espírito Santo. Vitória (ES): Sedu.

Esteban, M. T. (2008). Silenciar a polissemia e invisibilizar os sujeitos: indagações ao discurso sobre a qualidade da educação. Revista Portuguesa de Educaşão, Braga, 1(21), 5-31. Retirado em 10 de novembro de 2014, de <http://www.scielo.oces.mctes.pt/scielo.php? >. 


\section{pro.posições}

$e$-ISSN 1980-6248

http://dx.doi.org/10.1590/1980-6248-2016-0011

Esteban, M. T. (2012, setembro/dezembro). Considerações sobre a política de avaliação da alfabetização: pensando a partir do cotidiano escolar. Revista Brasileira de Educação, 51 (17), 573-592. Retirado em 20 de agosto de 2013, de <http://www.scielo.br/pdf/rbedu/v17n51/05.pdf >.

Fávero, L. L., Andrade, M. L. C. V. O., \& Aquino, Z. G. O. (2005). Oralidade e escrita: perspectiva para o ensino de língua materna. São Paulo: Cortez.

Freitas, D. N. T. de. (2007). A avaliação da educação básica no Brasil: dimensão normativa, pedagógica e educativa. Campinas, SP: Autores Associados.

Freitas, L. C. de. (2005, outubro). Qualidade negociada: avaliação e contra-regulação na escola pública. Educação e Sociedade, 92(26), 911-933. Número especial. Retirado em 2 de outubro de 2013, de <http://www.cedes.unicamp.br>.

Freitas, L. C. de. (2012, abril/junho). Os reformadores empresariais da educação: da desmoralização do magistério à destruição do sistema público de educação. Educação e Sociedade, 119(33), 379-404. Retirado em 20 de agosto de 2013, de <http://www.scielo.br/pdf/es/v33n119/a04v33n119.pdf>.

Freitas, L. C. de. (2013, janeiro/abril). Políticas de responsabilização: entre a falta de evidência e a ética. Cadernos de Pesquisa, 148(43), 348-365. Retirado em 10 de novembro de 2013, de $<$ http://educa.fcc.org.br/scielo $>$.

Geraldi, J. W. (2010). A aula como acontecimento. São Carlos, SP: Pedro \& João Editores.

Geraldi, J. W. (2013). O mundo não nos é dado, mas construído. In: Volochínov, V. N. $A$ construção da enunciação e outros ensaios (pp. 7-12). São Carlos, SP: Pedro e João Editores.

Gontijo, C. M. M. (2013, janeiro/abril). Alfabetização no ciclo inicial do ensino fundamental de nove anos: reflexões sobre as proposições do Ministério da Educação. Caderno Cedes, 89(33), 35-49. Retirado em 5 de outubro de 2013, de < http://www.cedes.unicamp.br>.

Mortatti, M. do R. L. (2013, janeiro/abril). Um balanço crítico da década da alfabetização no Brasil. Caderno Cedes, 89(33), 15-34. Retirado em 10 de agosto de 2013, de $<$ www.cedes.unicamp.br>.

Petrilli, S. (2013). Em outro lugar e de outro modo. Filosofia da linguagem, crítica literária e teoria da traducão em, em torno e a partir de Bakhtin. São Carlos, SP: Pedro e João Editores. 


\section{pro.posıções}

$e$-ISSN 1980-6248

http://dx.doi.org/10.1590/1980-6248-2016-0011

Ravitch, D. (2011). Vida e morte do grande sistema escolar americano: como os testes padronizados e o modelo de mercado ameaçam a educação. Porto Alegre: Sulina.

Sarmento, M. J. (2003). O estudo de caso etnográfico em educação. In Zago, N., Carvalho, M. P. de, \& Vilela, R. A. T. (Org.), Itinerários de pesquisa: perspectivas qualitativas em Sociologia de Educação (pp. 137-182). Rio de Janeiro: DP\&A.

Secretaria Estadual de Educação. (2012a). Manual do coordenador local alfa. Vitória, ES: Secretaria Estadual de Educação.

Secretaria Estadual de Educação. (2012b). Programa de Avaliação da Educação Básica do Espirito Santo Alfabetização: Manual do coordenador local. Vitória, ES: Secretaria Estadual da Educação.

Silva, V. G. da. (2008). Por um sentido público da qualidade na educação. 2008. Tese de Doutorado em Educação, Programa de Pós-Graduação em Educação, Universidade de São Paulo, São Paulo.

Volochínov, V. N. (2013). A construção da enunciação e outros ensaios. São Carlos, SP: Pedro \& João Editores.

Submetido à avaliação em 21 de março de 2016; revisado em 7 de agosto de 2016; aceito para publicação em 25 de setembro de 2016. 